\title{
MAIN CHALLENGES FOR THE BULGARIAN ARMED FORCES TRANSFORMATION
}

\author{
Stanimir TCHERNEV
}

\begin{abstract}
The author shares his views and thoughts on the transformation of the Bulgarian Armed Forces and the main challenges faced in the course of transformation in the dynamically changing security environment in the beginning of $21^{\text {st }}$ century. Special attention is paid to the important issues of transformation - capabilities development, modernization and professionalization of the Armed Forces.
\end{abstract}

Keywords: Armed Forces transformation, transformation challenges, modernization, professionalization.

The transformation of the Bulgarian Armed Forces (BAF) takes place as a result of the defence policy of the Republic of Bulgaria. In internal aspect, this environment is characterized by the functioning of a democratic political system with consensus on the main foreign policy goals and priorities, guaranteeing of the legal order and respect of the human rights and freedoms, consolidation of the market economy, ensuring development and individual security of the people.

In international aspect, the environment is characterized by multilateral influence of globalization and integration processes, internationalization of the risks and challenges, asymmetric threats, instability in some regions in the world and transformation in major international organizations (UN, NATO, EU, and OSCE) stemming out of this.

For optimal use of the opportunities and to effectively overcome the challenges of this environment, the Republic of Bulgaria follows a strategy based on non-traditional, preventive and proactive approaches and decisions of coordinated and mutually complemented efforts of engagement of the political, economic, technological, information, military and civilian resources of the country.

This strategy takes into account the integral nature of security and the integrated environment, in which it is guaranteed. 
This article will discuss the main issues posed before the Bulgarian Armed Forces in the process of transformation and the challenges for the Bulgarian Armed Forces transformation.

\section{Main Issues Posed before the Bulgarian Armed Forces in the Process of Transformation}

The transformation of the defence system takes place in parallel to the transformation in NATO.

The changes in the strategic military-political environment, the economic and demographic capabilities of the country and the national documents related to national security accelerated the implementation of the BAF development and transformation. This process has brought new requirements for building up and development of a modern BAF. The understanding of the BAF' role and place in the common defence system of the country has changed. In their development, the new integration and cooperation opportunities as factors forming the military strategic environment were taken into consideration.

The changed security environment imposed adaptation and gave a new meaning to the main role and tasks of the military factor as a main guarantee for security.

The character and tendencies in the security environment development required responsibility and engagement of all Alliance members. Keeping priority of the national political decision for missions and operations, member nations should give flexible and assured contribution by fair burden sharing for their implementation.

The implementation of the Alliance transformation goals and tasks depends and is related to the transformation of the member countries. The transformation of the Armed Forces means more than carrying out the reforms and acquiring new weapon systems. The transformation includes an accelerated technological modernization, doctrine development, restructuring of the forces, forming of new culture and will for change and taking risks. The transformation requires redefinition of the ways for combat power generation and its use, which leads to new approaches and ways for conducting military operations.

The main issues posed before the Bulgarian Armed Forces in the process of transformation are the building of capabilities required to respond to the realities and challenges of the $21^{\text {st }}$ century and the changes in the environment, the modernization and professionalization of the armed forces. At the same time, the Bulgarian Armed Forces continue to participate in NATO operations. 


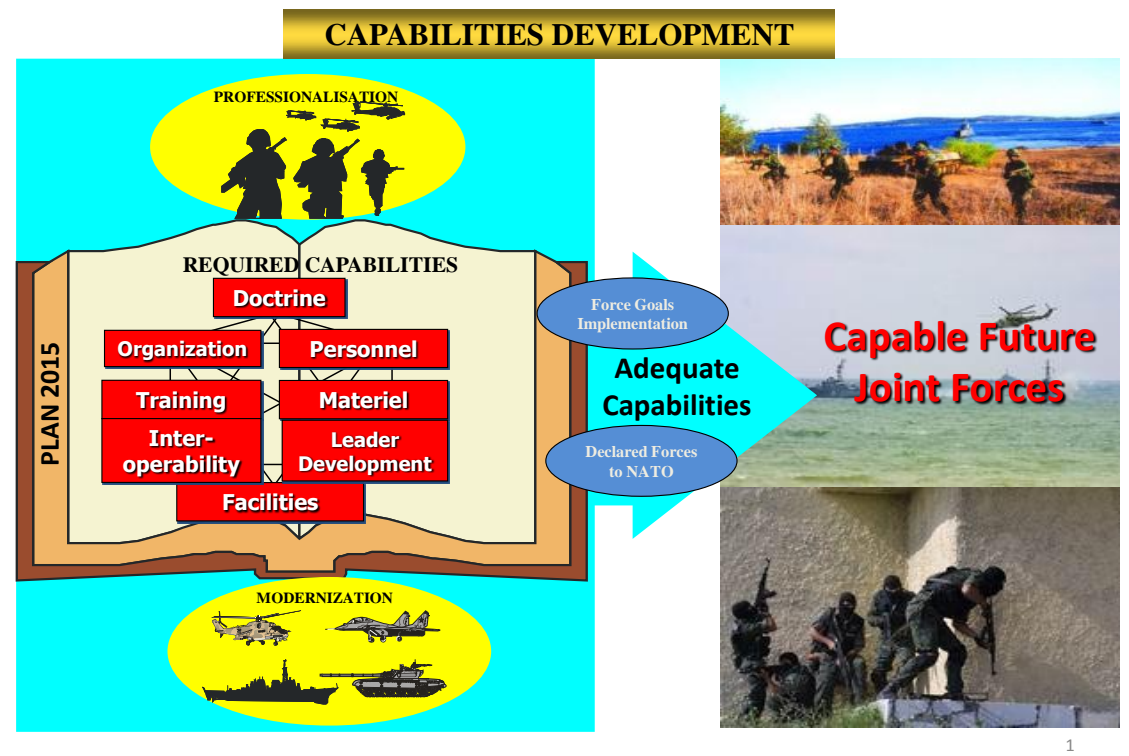

Figure 1: Capabilities Building and Development.

\section{Capabilities Building and Development}

The main goal of transformation is to optimize BAF' force structure for achieving a balance between tasks, structure, resources and effectiveness and enhancing their capabilities in accordance with the requirements of national defence and the NATO requirements for mobility, deployability and sustainability.

A primary task in the development and improvement of capabilities is the fulfilment of Force Goals, in compliance with the undertaken commitments and the terms for their accomplishment, with priority to the forces declared for the Alliance. The emphasis is on the timely and competent implementation of the authorized plans for realization of the adopted Force Goals and the criteria for usability. There is an ongoing actualization of the organization and strength of the declared forces in order to achieve the political objectives, adopted at the Istanbul Summit.

Force Goals implementation in the NATO Defence Planning process framework is realized by building of interoperable forces declared for the Alliance. They must have well defined tasks for use under the Alliance command and reliable and effective mechanism for manning and equipping them. It implies fulfilment of all requirements for training and education of the personnel and also adoption and execution of NATO military procedures and standards as well. 


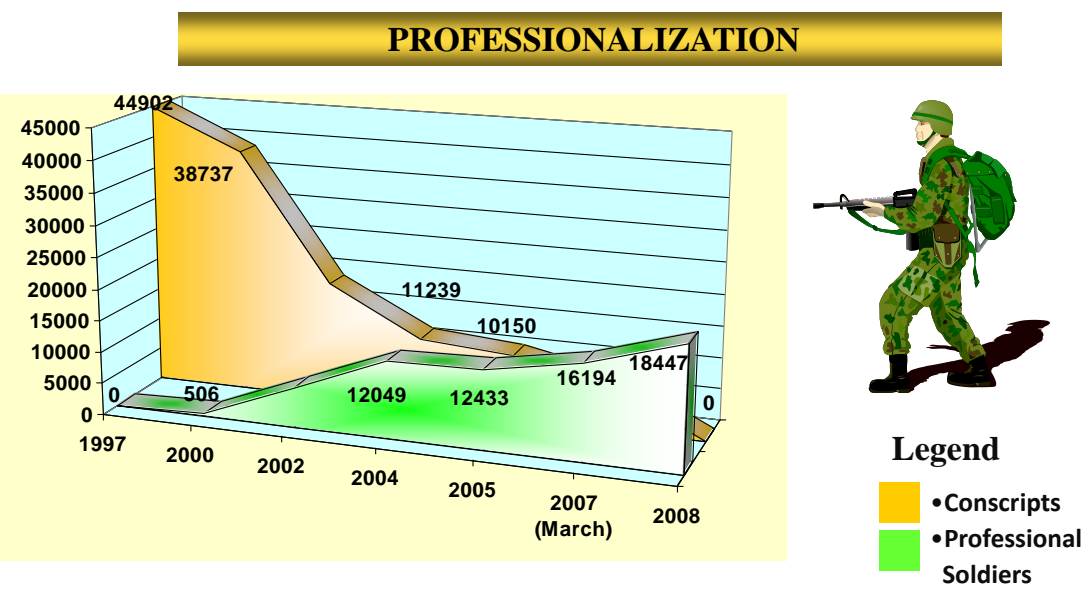

Figure 2: Professionalization of the Armed Forces in Figures.

In this context, Bulgaria is making and will continue to make efforts to provide adequate national participation in the formation of the collective policy of the Alliance and practical fulfilment of its commitments. The Bulgarian contribution to this transformation is measured by the accomplishment of the Force Goals, enhancement of the capabilities of the forces, their interoperability and usability, prioritized building, preparation and certification of the forces declared for participation in the full spectrum of NATO missions.

In addition to all above-mentioned issues, building of Host Nation capabilities packages and needed infrastructure is necessary.

An important element of the implementation of the Bulgarian Armed Forces transformation is the provision of strategic air and sea lift capabilities for in-time force deployment in the area of operation. In this sense, our participation in the C-17 initiative to meet the national requirements for strategic airlift is of significant importance.

\section{Professionalization of the Bulgarian Armed Forces}

An important part of the process of transformation of the Bulgarian Armed Forces is the process of professionalization of its personnel. With the decision adopted by the National Assembly on abolition of the conscript military service as of $1^{\text {st }}$ of January 2008, the Bulgarian Armed Forces still have to solve the issues on improvement of the process of recruitment of professional soldiers, qualitative selection, demanding training and motivation of the candidates for professional soldiers. The acceleration of this process is essential for all structures of the Bulgarian Armed Forces, but it mostly concerns the Land Forces, which will have to include a considerable number 


\section{MAJOR MODERNIZATION PROJECTS}
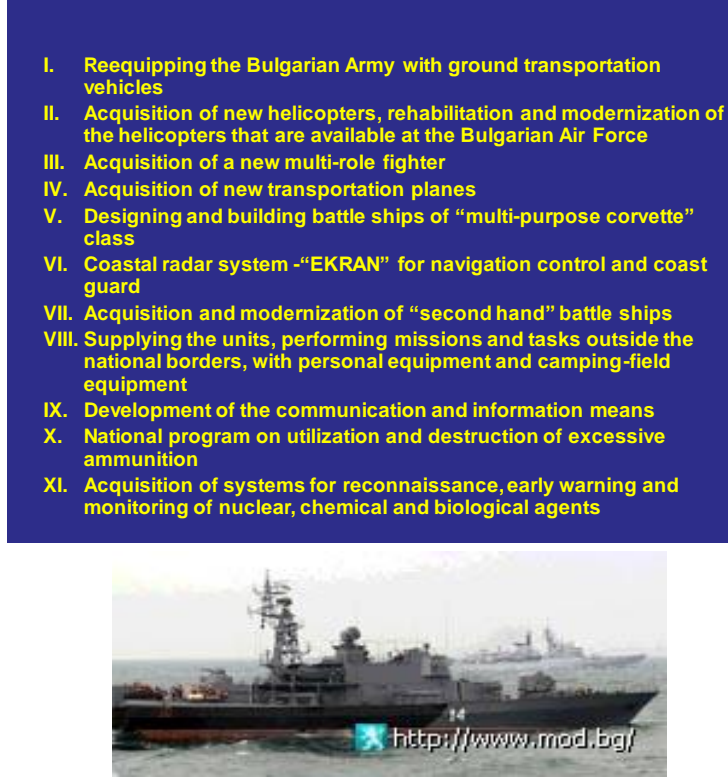
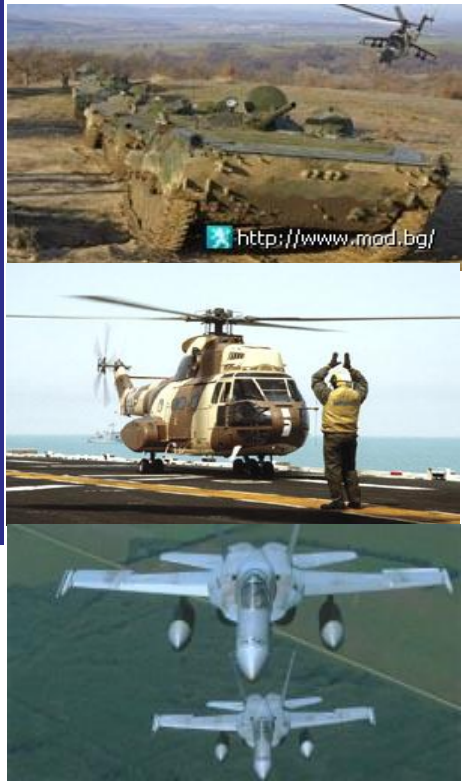

Figure 3: Major Modernization Projects of the Bulgarian Armed Forces.

of professional soldiers into their strength in a short period of time. This process has already been completed in the Navy and this Service is now fully professional.

The fact that the Armed Forces shall increasingly rely on volunteer forces suggests that substantial amount of financial resources has to be allocated in order to provide for their cost and for the increase of the personnel's quality of life, to include programmes for motivation, education, re-qualification and personal development after completion of contract duties.

\section{Modernization of the Bulgarian Armed Forces}

Modernization is the other main process regarded as decisive in the transformation of the Bulgarian Armed Forces. It is an essential element and centre of gravity in this process. The modernization will reduce the critical technological lagging and will provide up-to-date and effective armament and equipment for participation of our armed forces in a wide range of missions. A basic principle in the realization of modernization is the rational utilization of the capabilities of the national defence industry in the context of its international integration, on a beneficial basis, and the establishment of strategic relationships with leading corporations from NATO member states 
and the European Union. Recapitulation of the situation at the present moment indicates that only a few of the eleven priority investment projects (see Figure 3 ) have been actually initiated and are now in various stages of implementation. This fact entailed the necessity to prioritize the rest of the projects from a military-technical perspective. The ultimate goal is to get the most advantageous ratio between the project value and the actual acquired capabilities.

\section{Challenges to the Bulgarian Armed Forces Transformation}

The efficient development and functioning of the Bulgarian Armed Forces and the successful fulfilment of the requirements for its transformation is related to some of the challenges that we face in the course of transformation, appearing as a result of the need to strike a balance between desired defence potential, resources needed for its achievement and real capacity of the country to afford these capabilities.

The following challenges will be considered in what follows:

- Building of Armed Forces capable of implementing their assigned missions and tasks;

- Achieving and applying the NATO Standards and Procedures;

- Discrepancies between numerous requirements and limited defence resources;

- Training and education of the military personnel to meet the new requirements and challenges.

\section{Challenge \#1 - Building of Armed Forces Capable of Implementing Their Assigned Missions and Tasks}

For a successful continuation of the BAF' transformation, it is not only necessary to declare our willingness for acquiring new capabilities. We have to be ready and able to solve problems of internal and organizational nature and to provide to our country armed forces capable of implementing all tasks related to defending national security and interest and to the commitments to our allies as well. And we have to do this in the timeframe planned.

As a whole, we have the understanding that BAF' transformation is an integral part of NATO's transformation. The necessary functional relationship for our contribution to the alliance transformation and the use of conceptual and technical results from NATO strategic commands work has been created. For the implementation of the commitments to our allies we respond to the operational needs of the Alliance with Force Goals accepted by our country. 
The implementation of these tasks requires development of forces with capabilities for:

- Effective Intelligence;

- Deployability and Mobility;

- Effective Engagement;

- Effective Command, Control and Communications (C3);

- Logistics Sustainability;

- Interoperability;

- Survivability and Force Protection.

The adequate solution of this challenge is related to finding new ways and approaches to financial planning and expenditure management for the implementation of our obligations despite the lack of resources and finances.

\section{Challenge \#2 - Meeting the Requirements of NATO Standards and Certification Procedures}

Acquiring the Required Operational Capabilities is closely related to interoperability and the implementation of the accepted NATO standards. Special attention should be paid to the requirements of the NATO standards and certification procedures, as a basis for interoperability and capability for acting in a network environment.

\section{Challenge \#3 - Bridging the Gap between the Numerous Requirements and the}

\section{Limited Resources}

This is probably the most serious challenge. The successful transformation of the forces and capabilities for defence requires effective resource management. This calls for continuous optimization of the outlined priorities, as well as the funding schemes of the various projects.

We have to look for different ways and forms for financing of the BAF' modernization, with special programs, long-term governmental credits outside MOD's budget, etc.

Besides, it is necessary to consider the results of the NATO work, especially in the area of Concept Development and Experimentation.

The existing problems in the BAF logistics system, concerning the procurement of materials, their storage, proper use and accounting, the management of wartime supplies and the implementation of an automated logistic management system, have to be solved as soon as possible. 


\section{Transforming the Bulgarian Armed Forces for the $21^{\text {st }}$ Century}

Complex

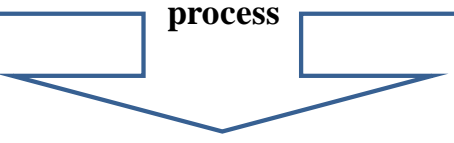

SMALLER NUMBER OF UNITS, FULLY MANNED AND EQUIPPED, SUSTAINED, PROTECTED; AGILE AND MOBILE READY FORCES

Figure 4: Goal of Transformation.

\section{Challenge \#4 - Preparation of Personnel Capable to Meet the New Requirements}

The realization of the priorities depends on the professional and personal characteristics of all people engaged in the transformation process. The people in the defence system are the most important factor for achieving the desired effect.

For improvement of the quality of the armed forces personnel, it is necessary to establish an effective working personnel management system. It should cover all processes of military personnel development and it should guarantee the application of the innovations in the military and civilian personnel career and qualification planning.

It is necessary to take some steps, including legal measures, to increase the attractiveness of military service as a whole and in particular the service in the units designated for participation in missions abroad. It should stipulate more opportunities for professional realization of the militaries. This will lead to increasing of the personnel motivation, professional engagement and self-confidence.

\section{Conclusion}

To summarize, the transformation of the Bulgarian Armed Forces is a complex process involving mindset changing, finding different approaches, changes in the standardization and doctrinal base, establishing new structures, developing new programmes for education and training, modernization and rearmament. 
As a result of the ongoing transformation, we plan to achieve a smaller number of formations, which are fully manned and equipped, capable to implement their tasks in the full spectrum of assigned missions.

Col. STANIMIR TCHERNEV is Deputy Chief of the "Strategic Planning" Directorate of the General Staff of the Bulgarian Armed Forces, overseeing the processes of defence planning and capability development. His distingushed military career as an Army officer combines tours in the field, variety of staff positions and extended tours in international headquarters, including the Partnership Coperation Cell in Mons, Belgium. All that experience combined provides for in-depth understanding of contemporary defence requirements and the challenges of defence transformation. 